\title{
XXXV. On the absorption-spectra of some copper salts in aqueous solution
}

\section{Thomas Ewan B.Sc. Ph.D.}

To cite this article: Thomas Ewan B.Sc. Ph.D. (1892) XXXV. On the absorption-spectra of some copper salts in aqueous solution, Philosophical Magazine Series 5, 33:203, 317-342, DOI: 10.1080/14786449208619999

To link to this article: http://dx.doi.org/10.1080/14786449208619999

曲 Published online: 08 May 2009.

Submit your article to this journal $\lceil\pi$

Џ Article views: 2

Q View related articles $\square$ 
T H E

\title{
LONDON, EDINBURGH, AND DUBLIN \\ PHILOSOPHICAL MAGAZINE
}

\author{
AND \\ JOURNAL OF SCIENCE.
}

[FIFTH SERIES.]

$A P R I L 1892$.

XXXV. On the Absorption-Spectra of some Copper Salts in Aqueous Solution. By Thomas Ewan, B.Sc., Ph.D., Dalton Scholar in Chemistry in the Owens College*.

THE following research was undertaken in the hope of 1 throwing some light on the question of the connexion between the absorption of light by salts in solution and their molecular structure.

On diluting a solution does a change in its absorptionspectrum take place? Whether this is so or not was the first point which I attempted to decide experimentally. A number of researches have already been carried out which bear on this question. The first of these is due to Beer $\dagger$, who came to the conclusion that a change in the concentration of a solution has the same effect as a corresponding change in the thickness of the layer through which the light passes. The measurements of Bunsen and Roscoet, and of Zöllner , were in agreement with Beer's law. Melde \|, in 1865 , found, by a qualitative method, that the law held good for dilute aqueous solutions of fuchsine; and the greater part of Vierordt's I measurements also agree with it.

* Communicated by the Author.

$\dagger$ Beer, Pogg. Ann. lxxxvi. p. 78 (1852).

$\ddagger$ Bunsen and Roscoe, Pogg. Ann. ci. p. 242 (1857).

§ Zöllner, Pogg. Ann. cix. p. 254 (1860).

il Melde, Pogg. Ann. cxxvi. p. 284 (1865).

- Vierordt, Die Anwendung des Spectralapparates, etc., 1873; Die Quantitative Spectralanalyse, etc., 1876.

Phil. Mag. S. 5. Vol. 33. No. 203. April 1892. Z 
Lippich *, in 1876 , observed that the absorption-spectrum of didymium nitrate is different in strong and in dilute solutions. This was subsequently confirmed by $\mathrm{H}$. Becquerel $\dagger$.

In 1878 Glan $\ddagger$ made a careful series of measurements on aqueous solutions of several salts in different concentrations. He found differences between the absorptions of strong and dilute solutions of about the magnitude of the experimental error.

Settegast $\$$, in 1879 , found a small decrease in the absorption of solutions of potassium chromate and potassium bichromate, with increasing dilution. This was in agreement with the observations of Glan; while Vierordt (loc. cil.), Sabatier \|, and $O$. Knoblauch $\Upsilon$ found a small increase in the absorption of the more dilute solutions.

o. Hesse ** (1880) examined alcoholic solutions of cyanine, and obtained numbers which did not agree with Beer's law. His experimental error appears to have been rather large, however ; and more recently Ketteler and Pulfrich $\dagger \dagger$ have shown that the law holds accurately for such solutions.

The measurements of Pulfrich" $¥ \ddagger$ and of Krüss $\S \S$ on potassium permanganate, and of Marshall||| and C. Norden था on carbonyl hæmoglobin and oxyhæmoglobin respectively, show that in these cases the extinction-coefficients are not strietly proportional to the concentrations.

The measurements of $\mathrm{B}$. Walter *** on solutions of fluorescein in ammonia show that Beer's law only holds good up to a certain concentration, above which deviations occur.

Knoblauch $\uparrow \dagger \uparrow$, finally, was unable to observe any difference between the spectra of strong and dilute solutions of a number of saits which he examined; in a number of other cases differences were observed.

* Lippich, Wien. Akad. Anz. 1876, p. 93.

$\dagger$ Becquerel, Compt. Rend. cii. p. 106' (1886).

$\ddagger$ Glan, Wied. Ann. iii. p. 54 (1878).

§ Settegast, Wied. Ann. vii. p. 242 (1879).

II Sabatier, Compt. Rend. ciif. p. 49 (1886).

T Knoblauch, Wied. Ann. xliii. p. 738 (1891).

** Hesse, Wied. Ann. xi. p. 871 (1880).

†† Ketteler and Pulfrich, Wied. Ann. xv. p. 337 (1882).

It Pulfrich, Wied. Ann. xiv. p. 177 (1881). (1891).

$\$$ Kri.ss, G. and H., Kolorimetrie u.Quantitative Spectralanalyse, p. 156

|| || J. Marshall, see Krüss, loc. cit. p. 211.

Tी C. Norden, see Krüss, loc. cit. p. 210.

*** B. Walter, Wied. Ann. xxxvi. p. 518 (1889)

t†† Knoblaứch, Wied. Ann. xliii. p. 738 (1891). 
It would appear, therefore, that the absorption-spectrum of a substance in solution is, as a rule, variable to a greater or smaller extent with the concentration.

The second question which received attention was the connexion between the spectra of the salts of the same acid or base in aqueous solution.

Gladstone *, in 1857, said that "a particular base or acid has the same effect on the rays of light, with whatever it may be combined in aqueous solution." This law, he found, held good generally though not invariably; and this conclusion was afterwards confirmed by the researches of $\mathrm{Bahr}$ and Bunsen $\dagger$, Bunsen $\ddagger$, Landauer $\S$, Morton and Bolton \|, Russel and Lapraik ๆ, Soret**, Russel $\uparrow \dagger$, Knoblauch, and others.

A discussion of a number of these papers is to be found in a Report on Spectrum Analysis by Dr. Schuster in the British Association Reports, 1882. I will therefore content myself by referring to it. Morton and Bolton found that a large group of double acetates of uranium possess the same absorption-spectrum. Knoblauch found in one experiment that the bands of the nitrate and acetate of uranium occupied the same position in dilute solutions, while in stronger solutions they had different positions. The chloride and acetate had the same spectrum. Russel and Lapraik found that the nature of the acid had no influence on the spectrum of uranic salts; while Oeffinger (Dissertation quoted by Knoblauch) apparently found no two salts of uranium with the absorption-bands in exactly the same position. The discrepancies are perhaps due to the different observers using solutions of different concentrations.

Knoblauch has shown that, even in the most dilute solutions, the spectra of the copper and potassium salts of eosin are not identical.

The photometric researches bearing on this question are very few in number. The work of Settegast $\ddagger \ddagger$ and of Sabatier $\S$ shows that potassium and ammonium bichromates

* Gladstone, Phil. Mag. (4) xiv. p. 418 (1857), and Journ. Chem. Soc. x. p. 79 (1858).

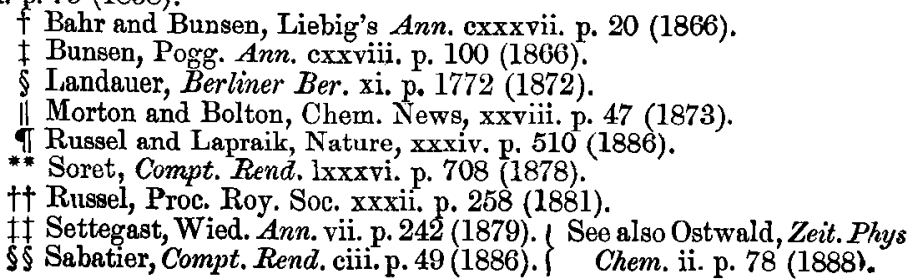


and chromic acid have very nearly the same absorptionspectrum, while that of potassium chromate is quite different.

Erhardt* found that the violet solutions of potassium and ammonium chrome-alums and of chromium sulphate have identical absorption-spectra, while that of chromic chloride is only very slightly different. The spectra of the other salts examined were considerably different.

As may be seen from the foregoing historical summary the experimental material is hardly sufficient to decide whether the absorptions of acid and base in aqueous solution are really independent or not. In strong solutions, speaking generally, they are not; but on dilution changes, greater or smaller, occur, and it is natural to inquire whether there is a limiting dilution beyond which no further change in the absorption occurs, and secondly, supposing that the limit exists, whether the acid and base will exercise their absorptions independently of each other in solutions more dilute than the limit.

To obtain answers to these questions, it was necessary to make photometric measurements of the fraction of the !light of each wave-length absorbed by a molecule of different salts of the same metal in solutions of different concentrations. The salts of copper were used, as they seemed to form a suitable material for the measurements.

A preliminary set of measurements was made by a method not unlike that used by ${ }^{\circ}$ Knoblauch $\dagger$, but I believe slightly more accurate, owing to the fact that it allows the spectra of the two solutions which are being compared to be seen simultaneously, side by side, in the spectroscope. A short description of it may therefore not be out of place.

The spectroscope used was a one-prism graduated arc instrument, by Hilger. The prism had a dispersion from $A$ to $\mathrm{H}$ of about $6^{\circ} 20^{\prime}$. The solutions were contained in troughs in such a way that a long layer of a dilute solution could be compared with a short layer of a correspondingly strong one. The lengths of the layers and the concentrations of the solutions were always taken inversely proportional to each other ; so that the light in both cases passed through the same amount of copper salt. In order that it should also pass through the same amount of water in each case, a long tube full of water was placed in front of the short tube con-

* Erhardt, Inaugural Iissertation, Freiberg, 1875 ?

$\uparrow$ These experiments were carried out in January and February 1891 ; that is, several months before Knoblauch's paper was published. 
taining the concentrated solution. The diagram, fig. 1, will make the arrangement sufficiently clear.

Fig. 1.

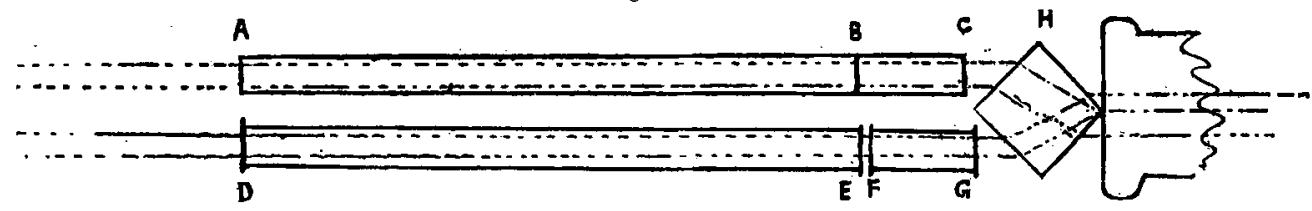

$\mathrm{A} \mathrm{B} \mathrm{C}$ is a trough having a movable water-tight partition of glass at $\mathrm{B}$. D E was the compensating-tube, full of distilled water ; F G the tube destined to contain the concentrated solution. $\mathrm{AB}$ and $\mathrm{DE}$ were each 888 millim. long, and $\mathrm{B} \mathrm{C}$ and F G each 102 millim. The light coming from a large Argand burner was rendered approximately parallel by means of a lens. The two bundles of light, after traversing the solutions, pass through the glass cube $\mathrm{H}$, by which means the two spectra are seen, the one above the other, and only separated by a narrow black band due to the edge of the cube, which was not quite sharp. The experiments were carried out as follows:-The tubes BC and F G were filled with a strong solution of, say, copper sulphate, and the tubes $A B$ and DE with distilled water. The volumes put into $A B$ and B C were proportional to the lengths of the two parts. The lamp was then arranged so that the two spectra appeared equally bright, and as nearly as possible the same in every respect; measurements of both were then made. The movable partition at $\mathrm{B}$ was then removed, the solution in $\mathrm{BC}$ mixed with the water in $A B$, the partition replaced, and measurements made again of the spectrum. By this means any change due to dilution which occurred would be detected. The absorption of the copper salts examined consists of a strong general absorption in the red, and a greater or smaller absorption in the violet and blue. The readings were made by means of a vertical fibre of silk in the eyepiece of the observing-telescope. The positions of the extreme ends of the luminous spectrum were read, and also the positions in which the silk fibre was just visible against the luminous background of the spectrum. The spaces between these readings were taken as the penumbra. The measurements made on the divided arc of the spectroscope were reduced to wave-lengths by interpolation in a curve constructed from measurements of various known lines, which were repeated from time to time. 
The following table contains the numbers obtained for copper chloride. Under $\lambda_{1}$ are the wave-lengths of the two positions read for concentrated solutions; under $\lambda_{2}$ the same readings for dilute solutions. The dilute solutions were about 10 the concentration of the strong solutions. The numbers are all the means of two or three readings, and the concentrations are given in gram-equivalents of salt in 1 litre of solution. The differences are taken so that a positive difference means an increase in the length of the visible spectrum, and vice versâ.

Table I.-Copper Chloride.

\begin{tabular}{|c|c|c|c||c|c|c|}
\hline $\begin{array}{c}\text { Con- } \\
\text { centration } \\
\text { of strong } \\
\text { solutions. }\end{array}$ & \multicolumn{3}{|c|}{ Violet end. } & \multicolumn{3}{|c|}{ Red end. } \\
\cline { 2 - 6 } & $\lambda_{1 \cdot}$ & $\lambda_{2} \cdot$ & $\lambda_{2}-\lambda_{2} \cdot$ & $\lambda_{1} \cdot$ & $\lambda_{2 \cdot}$ & $\lambda_{2}-\lambda_{1} \cdot$ \\
\hline \multirow{2}{*}{$4 \cdot 261$} & $478 \cdot 7$ & $429 \cdot 6$ & $+49 \cdot 1$ & $528 \cdot 4$ & $531 \cdot 2$ & $+2 \cdot 8$ \\
& $486 \cdot 8$ & $443 \cdot 0$ & $+43 \cdot 8$ & $543 \cdot 2$ & $540 \cdot 8$ & $-2 \cdot 4$ \\
$2 \cdot 1305$ & $451 \cdot 0$ & $439 \cdot 0$ & $+12 \cdot 0$ & $537 \cdot 2$ & $539 \cdot 6$ & $+2 \cdot 4$ \\
& $463 \cdot 0$ & $451 \cdot 0$ & $+12 \cdot 0$ & $551 \cdot 6$ & $552 \cdot 4$ & $+0 \cdot 8$ \\
$1 \cdot 7044$ & $431 \cdot 0$ & $427 \cdot 6$ & $+3 \cdot 4$ & $572 \cdot 0$ & $567 \cdot 8$ & $-4 \cdot 2$ \\
& $444 \cdot 6$ & $437 \cdot 2$ & $+7 \cdot 4$ & $576 \cdot 4$ & $579 \cdot 4$ & $+3 \cdot 0$ \\
$1 \cdot 3612$ & $426 \cdot 2$ & $421 \cdot 0$ & $+5 \cdot 2$ & $575 \cdot 2$ & $575 \cdot 0$ & $-0 \cdot 2$ \\
& $435 \cdot 8$ & $428 \cdot 0$ & $+7 \cdot 8$ & $579 \cdot 8$ & $577 \cdot 4$ & $-2 \cdot 4$ \\
$1 \cdot 227$ & $424 \cdot 0$ & $415 \cdot 4$ & $+8 \cdot 6$ & $580 \cdot 6$ & $580 \cdot 6$ & \pm 0 \\
& $430 \cdot 6$ & $427 \cdot 0$ & $+3 \cdot 6$ & $584 \cdot 0$ & $584 \cdot 0$ & $\overline{\overline{7}}$ \\
$1 \cdot 018$ & $414 \cdot 8$ & $412 \cdot 4$ & $+2 \cdot 4$ & $596 \cdot 6$ & $596 \cdot 6$ & \pm 0 \\
& $420 \cdot 8$ & $417 \cdot 8$ & $+3 \cdot 0$ & $602 \cdot 0$ & $602 \cdot 0$ & $\overline{+} 0$ \\
\hline
\end{tabular}

The temperature varied from $15^{\circ}$ to $17^{\circ} .2$ on different days. The wave-length of the extreme violet end of the spectrum when the trough was filled with distilled water was found (on different days) $416 \cdot 0,417 \cdot 2$, and $411 \cdot 2$. This show's that the more dilute solutions transmitted the whole of the violet light. The average difference of a single reading from the mean was about \pm 1.5 units in the wave-length.

The above numbers show that the position of the absorption at the red end of the spectrum does not vary with dilution. The differences vary irregularly in sign, and are of about the magnitude of the experimental error. The absorption in the violet (which extends into the green in the case of the strongest solution) disappears on dilution, so that a layer of 102 millim. of a solution containing about 1 gram-equivalent of salt in a litre shows no noticeable absorption. No change can, of course, be seen on further dilution; it would, however, be 
rash to conclude that the change has reached a limit at a dilution of 1 gram-equivalent in a litre, as with an Argand burner the visible spectrum only extends to about halfway between $\mathrm{G}$ and $\mathrm{H}$; it probably goes on till much greater dilutions are reached, only in the ultra-violet.

TABLE II.

\begin{tabular}{|c|c|c|c|c|c|c|}
\hline \multicolumn{7}{|c|}{$\mathrm{CuSO}_{4}$. } \\
\hline \multirow{2}{*}{$\begin{array}{l}\text { Con- } \\
\text { centration } \\
\text { of strong } \\
\text { solution. }\end{array}$} & \multicolumn{3}{|c|}{ Violet end. } & \multicolumn{3}{|c|}{ Red end. } \\
\hline & $\lambda_{1}$. & $\lambda_{2}$ & $\lambda_{1}-\lambda_{2}$ & $\lambda_{1}$. & $\lambda_{2}$ & $\lambda_{2}-\lambda_{1}$. \\
\hline 1.89 & $\begin{array}{l}419 \cdot 2 \\
428 \cdot 0\end{array}$ & $\begin{array}{l}419 \cdot 2 \\
427 \cdot 4\end{array}$ & $\begin{array}{l} \pm 00 \\
+0.6\end{array}$ & $\begin{array}{l}557 \cdot 0 \\
568 \cdot 4\end{array}$ & $\begin{array}{l}557 \cdot 3 \\
568 \cdot 4\end{array}$ & $\begin{array}{r}+0.3 \\
\pm 0.0\end{array}$ \\
\hline \multicolumn{7}{|c|}{$\mathrm{Cu}\left(\mathrm{NO}_{3}\right)_{2}$} \\
\hline $4 \cdot 4323$ & $\begin{array}{l}429 \cdot 0 \\
440 \cdot 2\end{array}$ & $\begin{array}{l}429 \cdot 7 \\
438 ; 3\end{array}$ & $\begin{array}{r}-0.7 \\
+1.9\end{array}$ & $\begin{array}{l}525 \cdot 7 \\
527.8\end{array}$ & $\begin{array}{l}525.7 \\
527.8\end{array}$ & $\begin{array}{l}0 \cdot 0 \\
0 \cdot 0\end{array}$ \\
\hline
\end{tabular}

The concentration appears to have no influence on the spectra of copper sulphate and nitrate. This agrees with the results of Knoblauch; but, as will be seen later, this is not quite accurate, the concentration really exerting a small influence on the spectra.

Comparisons of the absorptions of $\mathrm{CuCl}_{2}$ and $\mathrm{Cu}\left(\mathrm{NO}_{3}\right)_{2}$ in tolerably dilute solutions showed that no appreciable difference exists between them. The numbers obtained are given in Table III. (p. 324).

This method of merely comparing the limits of the spectra of two solutions does not appear to be sufficiently accurate. It is quite possible that general absorptions may exist in a spectrum which, not being sufficiently large to altogether extinguish the light at any place, may pass unnoticed. For example, the photometric measurements made on a strong solution of copper nitrate showed that it exerts a small general absorption over the violet part of the spectrum. This entirely escaped detection by the method described.

According to B. Walter *, the width of the penumbra round an absorption-band is connected closely with the presence of

* B. Walter, Wied. Ann. xxxvi. p. 523 (1889). Compare Böhlendorff, Wied. $A n n$. xliii. p. 784 (1891). 


\begin{tabular}{|c|c|c|}
\hline$\stackrel{200}{0}$ & ت & 落 \\
\hline ণั) & 落 & $\stackrel{\oplus}{=}$ \\
\hline$\stackrel{\stackrel{\rho}{9}}{\dot{\theta}}$ & 茫 & $\stackrel{P}{i}$ \\
\hline$\underset{0}{\stackrel{0}{0}}$ & $\stackrel{\varphi}{=}$ & $\dot{\phi}$ \\
\hline ஷุ่ & $\stackrel{\infty}{\stackrel{\infty}{\beth}}$ & 올 \\
\hline$\stackrel{+}{\dot{0}}$ & $\ddot{\dot{\infty}}$ & $\stackrel{+}{\dot{g}}$ \\
\hline sị & Hi⿱ & $\stackrel{\circ}{\circ}$ \\
\hline$\stackrel{\leftrightarrow}{\leftrightarrow}$ & $\stackrel{\varphi}{\dot{H}}$ & $\stackrel{\varphi}{ \pm}$ \\
\hline 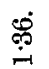 & $\stackrel{\infty}{\dot{+}}$ & $\dot{\sigma}$ \\
\hline 菅 & $\ddot{+}$ & $\dot{\phi}$ \\
\hline 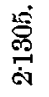 & 贲 & ঙ્ડ \\
\hline 灾 & $\stackrel{\infty}{\stackrel{\infty}{+}}$ & $\vec{\infty}$ \\
\hline 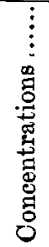 & 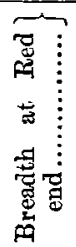 & 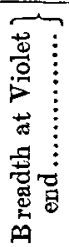 \\
\hline
\end{tabular}


more complex molecular aggregates in the solution. On diluting a strong solution of copper chloride, he found a sudden change, at a certain point, in the width of the penumbra, due to the breaking-up of the complex molecules. Table IV. (p. 324) contains the measurements of the breadth of the penumbra, calculated from Table I., for a number of solutions of copper chloride.

On the whole the numbers cannot be regarded as showing any sudden diminution in the breadth of the penumbra. The variations appear to be accidental, and are probably due to variations in the brightness of the spectra caused by alterations in the relative positions of the lamp and the tubes containing the solutions.

\section{Photometric Results.}

The method of Vierordt was employed, the instrument used being a universal spectro-photometer by A. Krüss of Hamburg: As this instrument has already been described elsewhere *, no lengthy description of it will be necessary. The apparatus consists of an ordinary spectroscope, the slit of which is divided into two halves, each of which opens symmetrically, and in an accurately measurable manner, by means of micrometer-screws, the heads of which carry circles divided into 100 parts. By this means it is possible to vary the brightness of the upper and lower halves of the spectrum independently of each other by varying the width of the slits. A second slit in the eyepiece of the observing-telescope makes it possible to cut out a band in any part of the spectrum. The position of the centre and of the edges of this slit (which also opens symmetrically) can be read off by means of micrometer-screws.

The ocular slit was opened 56 divisions (on its screw), which corresponds to a breadth of about $0 \cdot 27$ millim. This divided the whole length of the visible spectrum into 19 parts, in each of which measurements were made.

For an account of the precautions which must be taken in using the instrument it will be sufficient to refer to the works of G. and H. Krüss and of Vierordt, more especially Die Anwendung des Spectralapparates zur Photometrie der Absorptions-spectren (Tübingen, 1873).

The solutions were contained in cells of various lengths. As the measurements are most accurate when the absorption lies between 50 and 85 per cent. of the total light, the length

* Berichte, xix. p. 2739 (1886); Zeitschrift anal. Chem. xxi. p. 182 (1882); G. \& H. Kruiss, Kolorimetrie, p. 90 et seq. 
of layer was chosen so that the absorptions to be measured should as often as possible fall between these limits. Three cells were used-viz. a Schulz cell, the glass cube of which had a thickness of 1.006 centim., and two troughs, $7 \cdot 64$ and 22. 86 centim. long respectively. When using these troughs the liquid only filled the lower half, the meniscus being placed at the level of the division between the two halves of the double slit. As, however, this produces a black band, about 2 millim. broad, between the two spectra, thereby greatly increasing the difficulty of comparing their brightness, a flintglass rhomb was placed between the trough and the slit, in the same way as in Hüfner's spectro-photometer*. The arrangement is shown in fig. 2.

Fig. 2.

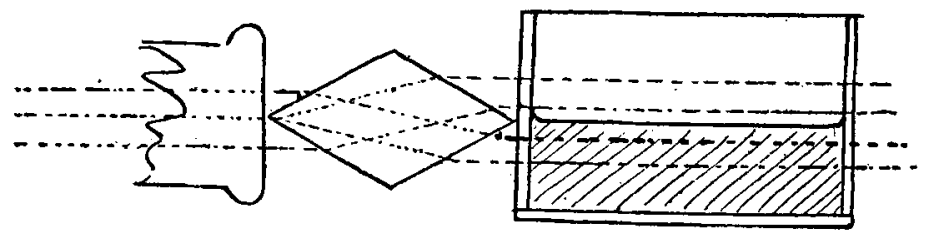

The ends of the trough were provided with screens of blackened card of sufficient width to prevent reflexions from the sides of the trough or from the meniscus. The sonrce of light was, as before, the Argand burner. The measurements were made in a dark room, and extraneous light shut off from the apparatus as much as possible by screens, and from the eye of the observer by a piece of black velvet which covered the eyepiece of the observing-telescope. The light from the Argand burner was concentrated by means of two lenses on a hole, about $\frac{1}{16}$ inch diameter, in a black screen, and after passing this was made parallel by a lens of about 15 inches focal distance. The light thus obtained was rather faint, but it was not found possible to obtain reliable results otherwise. The salts examined were carefully purified and the solutions made with twice distilled water. They were filtered immediately before being examined through fine Swedish filterpaper. All the solutions were analysed after being filtered, as the filtration made a small difference in the concentration. The analyses were made by the very convenient methodtitration, with thiosulpbate solution, after adding excess of potassium iodide-described by Westmoreland ${ }^{\circ}$. The con-

* Zeit. Phys. Chem. iii. p. 562 (1889).

† Journ. Soc. Chem. Ind. 1886, p. 48. 
centrations are, as before, given in gram equivalents in one litre of solution.

The measurements are made as follows :-The cell, either empty or filled with distilled water, is adjusted before the slit of the spectroscope on a suitable stand, and the ratio of the intensities of the light which has passed through the upper and lower halves of the trough is read, in various parts of the spectrum. This gives the correction to be applied on account of the apparatus. The solution is now placed in the trough, and readings made through as much of the spectrum as possible. Ten or more single readings were made in each region and the mean taken.

The formulæe which I have used in reducing the results are:-(1) For the Schulz cell,

$$
(1-p)=\frac{b\left(1-\beta^{\prime \prime \prime}\right)^{2}}{\left(1-\beta^{\prime}\right)^{2} \cdot a}
$$

(2) For the ordinary troughs,

where

$$
(1-p)=\frac{b(1-\beta)^{2}}{\left(1-\beta^{\prime \prime}\right)^{2}\left(1-p^{\prime}\right) \cdot a} ;
$$

$$
\begin{aligned}
& a=\frac{\text { width of lower slit }}{\text { width of upper slit' the two spectra having been made }} \\
& \text { of equal brightness, and the empty trough being before } \\
& \text { the slit. }
\end{aligned}
$$

$b$ is the same ratio when the trough contains the solution.

$p$ the fraction of the incident light absorbed by the dissolved substance.

$p^{\prime}=$ the fraction absorbed by the water.

$\beta=$ loss by reflexion at surface between ends of trough and air.

$\beta^{\prime}=$ loss by reflexion at surface between Schulz cube and air.

$\beta^{\prime \prime}=$ loss by reflexion at surface between ends of trough and solution.

$\beta^{\prime \prime \prime}=$ loss by reflexion at surface between Schulz cube and solution.

The loss of light due to the absorption of the water was calculated from the numbers of Hüfner and Albrecht*. The following table contains the numbers which were used in reducing the results.

* Wied. Ann. xlii. p. 1 (1891). 
TABLE V.

\begin{tabular}{|c|c|c|c|}
\hline $\begin{array}{l}\text { Region in } \\
\text { Spectrum. }\end{array}$ & $\epsilon$. & $\begin{array}{c}\left(1-p^{\prime}\right) \\
\text { for } 7 \cdot 64 \text { centim }\end{array}$ & $\begin{array}{c}\left(1-p^{\prime}\right) \\
\text { for } 22: 87 \text { centim. }\end{array}$ \\
\hline 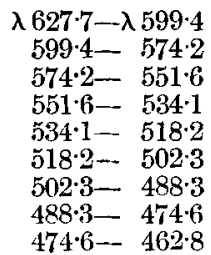 & $\begin{array}{l}0 \cdot 00108 \\
0 \cdot 00073 \\
0 \cdot 00039 \\
0 \cdot 00026 \\
0 \cdot 00019 \\
0 \cdot 00018 \\
0 \cdot 00017 \\
0 \cdot 00016 \\
0 \cdot 00015\end{array}$ & $\begin{array}{l}0.981 \\
0.987 \\
0.993 \\
0.996 \\
0.997 \\
0.997 \\
0.998 \\
\ldots \ldots . \\
\ldots \ldots .\end{array}$ & $\begin{array}{l}\ldots \ldots \\
\ldots \ldots . . \\
0.980 \\
0.986 \\
0.990 \\
0.990 \\
0.991 \\
0.992 \\
0.993\end{array}$ \\
\hline
\end{tabular}

The quantity $(1-p)$ is the fraction of the incident light which has escaped being absorbed by the dissolved substance, and is dependent on the length of layer and concentration of solution. In order to obtain comparable numbers, the extinction-coefficients and absorption-ratios have been calculated from the values of $(1-p)$. A few words on the connexion of these quantities with one another are perbaps not altogether superfluous.

According to Lambert's law we have

$$
\mathrm{I}^{\prime}=\mathrm{I} \alpha^{n}, \text {. . . . . . . }
$$

where $I^{\prime}$ is the light transmitted by a layer of thickness $n$, of a substance the coefficient of transmission of which is $\alpha . I$ is the original intensity of the light.

Bunsen and Roscoe* define the extinction-coefficient as the reciprocal of that length of layer of a solution which will reduce the intensity of light by absorption to $\frac{1}{10}$ of its original value.

Substituting, therefore, in equation (1), $I^{\prime}=\frac{1}{10}, I=1$, and $n=\frac{1}{\epsilon}$, we get $\quad \frac{1}{10}=\alpha^{\frac{1}{\epsilon}}$,

or

$$
\epsilon=-\log \alpha . \quad . \quad . \quad . \quad . \quad .
$$

From equation (1) we have also

$$
-n \log \alpha=\log \mathrm{I}-\log \mathrm{I}^{\prime} \text {. }
$$

Substituting the value of $-\log \alpha$ and putting $I=1$, we get

$$
\epsilon=-\frac{\log \mathrm{I}^{\prime}}{n} \text {. }
$$

$\mathrm{I}^{\prime}$ is the quantity which before has been called $(1-p)$.

* Pogg. Ann. ci. p. 235 (1857). 
Further, according to Beer's law, if there are two solutions of the same substance, of concentrations $c$ and $c^{\prime}$, and in lengths of layer $l$ and $l^{\prime}$, such that

$$
c l=c^{\prime} l^{\prime}, \quad \cdot \quad \cdot \text {. . }
$$

they will absorb the same fraction of the light which passes through them.

Suppose they both transmit the fraction $\mathrm{I}^{\prime}$, then

$$
\epsilon=-\frac{\log \mathrm{I}^{\prime}}{l} \text { and } \epsilon^{\prime}=-\frac{\log \mathrm{I}^{\prime}}{l^{\prime}}, \ldots .
$$

$\epsilon$ and $\epsilon^{\prime}$ being the extinction-coefficients of the two solutions. From (1) we find

$$
-\frac{c l}{\log \bar{I}^{\prime}}=-\frac{c^{\prime} l^{\prime}}{\log \mathbf{I}^{\prime}} ; \quad \text {. . . . . }
$$

and from (2) and (3), finally, we have

$$
\frac{c}{\epsilon}=\frac{c^{\prime}}{\epsilon^{\prime}} \text {. }
$$

That is, the concentration is proportional to the extinctioncoefficient, and $\frac{e}{\epsilon}=\mathrm{A}$. A is, if Beer's law is true, a constant only dependent on the wave-length of the light and on the nature of the substance. The quantity $\AA$ is called by Vierordt the absorption-ratio (Absorptions-verhältniss).

The following example will make the method of reducing the results clear :--

Solution of $\mathrm{CuCl}_{2}$, concentration $=2 \cdot 113 \mathrm{gr}$. eq. in 1 litre.

Trough $7 \cdot 64$ centim. long.

The apparatus-correction $a$ was found 1.003 , as a mean of

\begin{tabular}{|c|c|c|c|c|}
\hline $\begin{array}{l}\text { Breadth of } \\
\text { upper slit. }\end{array}$ & $\frac{\text { Lower slit }}{\text { Upper slit }}$ & $\begin{array}{l}\text { Number of } \\
\text { Readings. }\end{array}$ & $\begin{array}{c}\text { Greatest } \\
\text { difference } \\
\text { between two } \\
\text { Readings. }\end{array}$ & Mean (b). \\
\hline 140 & $\cdot 484$ & 5 & $3 \cdot 87$ & \multirow{2}{*}{0.485} \\
\hline 100 & $\cdot 487$ & 5 & $2 \cdot 3\}$ & \\
\hline
\end{tabular}
25 readings in various positions in the spectrum.

The following readings were taken with the solution in the trough, in the region between $\lambda 518 \cdot 2$ and $\lambda 502 \cdot 3$.

The refractive index of the ends of the trough was 1.526 . 
$\beta$ and $\beta^{\prime \prime}$ are calculated by Fresnel's formula- $\left(\frac{n-1}{n+1}\right)^{2}$, which gives $\beta=0.0433$ and $\beta^{\prime \prime}=0.00325$. The fraction of light transmitted by $7 \cdot 64$ centim. of water is taken from Table V. Putting these values into the expression given for the ordinary troughs, we get

$$
\begin{aligned}
(1-p) & =\frac{0.485 \times(1-0.0433)^{2}}{(1-.00325)^{2} \times 0.997 \times 1.003} \\
& =0.4473 .
\end{aligned}
$$

As

$$
\epsilon=-\frac{\log (1-p)}{l}
$$

where $l=$ length of layer,

$$
\begin{aligned}
l \epsilon & =-\log (1-p) \\
& =0.34944 .
\end{aligned}
$$

Again,

$$
A=\frac{c}{\epsilon}=\frac{c l}{\epsilon l} ;
$$

$\log A=\log c+\log l-\log e l$

$$
=\log (2 \cdot 113)+\log (7 \cdot 64)-\log (0 \cdot 34944) ;
$$

$c=$ concentration in gram equivalents in 1 litre of solution. On calculating out the above expression,

$$
\mathrm{A}=46^{\circ} 2 \text {. }
$$

\section{Probable Error.}

\begin{tabular}{|c|c|c|c|c|}
\hline $\begin{array}{l}\text { Region in } \\
\text { Spectrum. }\end{array}$ & $\begin{array}{l}\text { Number of } \\
\text { Readings. }\end{array}$ & $(1-p)$ & Y. & Z. \\
\hline $\begin{array}{l}551 \cdot 6-534 \cdot 1 \\
534 \cdot 1-518 \cdot 2 \\
518 \cdot 2--502 \cdot 3 \\
502 \cdot 3-488 \cdot 3 \\
488 \cdot 3-474 \cdot 6 \\
474 \cdot 6-462 \cdot 8 \\
462 \cdot 8-452 \cdot 2 \\
452 \cdot 2-443 \cdot 1 \\
443 \cdot 1-434 \cdot 2\end{array}$ & $\begin{array}{r}15 \\
15 \\
10 \\
15 \\
15 \\
10 \\
10 \\
10 \\
5\end{array}$ & $\begin{array}{l}0 \cdot 083 \\
0 \cdot 2599 \\
0 \cdot 4855 \\
0 \cdot 7020 \\
0 \cdot 7972 \\
0 \cdot 7676 \\
0 \cdot 6125 \\
0 \cdot 3893 \\
0 \cdot 1890\end{array}$ & $\begin{array}{c} \pm 0 \cdot 0014 \\
.0016 \\
.00289 \\
.00371 \\
.00469 \\
.00616 \\
.00410 \\
.00576 \\
.00334\end{array}$ & $\begin{array}{r} \pm 3 \cdot 5 \\
1.3 \\
1.3 \\
1 \cdot 1 \\
1.3 \\
1 \cdot 7 \\
1 \cdot 5 \\
3.5 \\
3 \cdot 7\end{array}$ \\
\hline
\end{tabular}

As there is no reason why the error should be greater in one set of measurements than in another (the measurements being all of the same kind), I have only calculated it for one set of numbers, obtained with a solution of copper chloride containing $2 \cdot 113$ equiv. in 1 litre. The probable error was calculated by the formula $\pm 0.6745 \sqrt{\frac{\mathrm{S}}{n(n-1)}}$. The results
are contained in Table VI.

TABLE VI. 
The final value of $(1-p)$ is calculated from two photometric measurements of the same kind; one, the correction for the apparatus, the other the measurement of the light which passes through the solution. These will both be subject to an error of the magnitude given in column Y. The probable error of the final result will therefore be double this amount. The numbers in column $\mathrm{Z}$ represent this final error, calculated as percentages of $(1-p)$. The large error in the violet is due to the small intensity of the light used in that part of the spectrum, and also to the fact that the eye is less sensitive to differences in the intensity of light in the violet than in the middle of the spectrum. At the red end of the spectrum a special error makes itself felt. The measurements are only theoretically accurate, when the part of the curve representing the intensity of the light in the part of the spectrum in which they are made may be considered as a horizontal line. When the absorption-curve of the substance under examination rises or falls rapidly this is no longer the case, and for this reason the measurements on the copper salts in the red end of the spectrum are less accurate than in other parts.

My first measurements on the absorptions by copper sulphate showed a lack of agreement between the numbers obtained with the same solution when different lengths of layer were used. This was found to be due to the light not being parallel, as the differences disappeared when parallel light was used. Something similar appears to have been observed by other investigators. Vierordt* found (with a lamp 15 centim. from the slit, and distilled water in the trough) the ratio of the intensity of the light which had passed through the empty half of the trough to that which had passed through the water to be 0.8 ; the calculated number is 0.936 . Krüss $\dagger$ found the ratio in a Schulz cell 0.905 , that calculated being $0 \cdot 993$. I also found the ratio in a Schulz cell $0 \cdot 91$, when the light was not parallel.

The cause of these differences may be found in the fact that placing a layer of a medium with a greater refractive index than air in the path of the light has the same effect as bringing the light nearer to the slit through a distance which is given by the formula $l\left(\frac{\mu-1}{\mu}\right)$, where $l$ is the thickness of the layer of the medium, and $\mu$ its refractive index. It must also be remembered that, so long as the collimator is filled with light, an alteration in the distance of the lamp makes no difference in the intensity of the light in the spectrum. The

* Anwendung \&c. pp. 5 and 24.

† Kolorimetrie, p. 153. 
distance of the lamp must therefore be measured from the point at which the collimator just ceases to be filled with light. A comparison with a set of measurements made with pure water showed that at least a considerable part of the difference observed is to be explained in this way.

The following Tables contain a number of measurements which were made with parallel light and distilled water in the troughs. The good agreement found between the calculated and observed numbers shows that the loss of light due to dust in the liquids cannot have been very great. I is the ratio of the intensities of the light after passing through the upper and lower halves of the trough.

TABLE VII.

\begin{tabular}{|c|c|c|c|}
\hline $\begin{array}{l}\text { Region in } \\
\text { Spectrum. }\end{array}$ & $I$ (found). & I (calculated) & Difference. \\
\hline \multicolumn{4}{|c|}{ Schulz Cell. } \\
\hline $\begin{aligned} \lambda 599 \cdot 4-\lambda & 574 \cdot 2 \\
551 \cdot 6- & 534 \cdot 1\end{aligned}$ & $\begin{array}{l}0.985 \\
0.991\end{array}$ & $\begin{array}{l}0 \cdot 987 \\
0.985\end{array}$ & $\begin{array}{l}+0.002 \\
-0.006\end{array}$ \\
\hline \multicolumn{4}{|c|}{ Schalz Cell. } \\
\hline $\begin{array}{r}\lambda 627 \cdot 7-\lambda 599 \cdot 4 \\
599 \cdot 4-574 \cdot 2 \\
574 \cdot 2-551 \cdot 6 \\
551 \cdot 6-534 \cdot 1 \\
518 \cdot 2-502 \cdot 3\end{array}$ & $\begin{array}{l}0.983 \\
0.979 \\
0.982 \\
0.985 \\
0.988\end{array}$ & $\begin{array}{l}0.987 \\
0.987 \\
0.986 \\
0.985 \\
0.985\end{array}$ & $\begin{array}{l}+0.004 \\
+0.008 \\
+0.004 \\
\pm 0.000 \\
=0.003\end{array}$ \\
\hline \multicolumn{4}{|c|}{ Layer of water, $7 \cdot 64$ centim. } \\
\hline $\begin{array}{rr}\lambda 627 \cdot 7-\lambda & 599 \cdot 4 \\
599 \cdot 4- & 574 \cdot 2 \\
574 \cdot 2- & 551 \cdot 6 \\
551 \cdot 6- & 534 \cdot 1 \\
534 \cdot 1- & 518 \cdot 2 \\
502 \cdot 3- & 488 \cdot 3 \\
488 \cdot 3- & 474 \cdot 6\end{array}$ & $\begin{array}{l}0.949 \\
0.939 \\
0.948 \\
0.935 \\
0.926 \\
0.909 \\
0.919\end{array}$ & $\begin{array}{l}0.941 \\
0.935 \\
0.929 \\
0.927 \\
0.926 \\
0.926 \\
0.926\end{array}$ & $\begin{array}{l}-0.008 \\
-0.004 \\
-0.019 \\
-0.008 \\
\pm 0.000 \\
+0.017 \\
+0.007\end{array}$ \\
\hline \multicolumn{4}{|c|}{ Layer of water, $22 \cdot 87$ centim. } \\
\hline $\begin{array}{r}\lambda 534 \cdot 1-\lambda 518 \cdot 2 \\
502 \cdot 3-488 \cdot 3 \\
474 \cdot 6-462 \cdot 8\end{array}$ & $\begin{array}{l}0.927 \\
0.925 \\
0.917\end{array}$ & $\begin{array}{l}0.934 \\
0.933 \\
0.931\end{array}$ & $\begin{array}{l}+0.007 \\
+0.008 \\
+0.014\end{array}$ \\
\hline
\end{tabular}

The effect of dust would be to make the observed numbers higher than those calculated. This is sometimes the case, sometimes the reverse. 
Table VIII. contains the details of the measurements made on the solutions of copper salts.

Under $c$ are found the concentrations of the solutions, in gram equivalents of salt in 1 litre of solution; under $l$ the length of layer in centim. ; $\epsilon$ is the extinction-coefficient, and A the absorption-ratio.

TABLE VIII.

\begin{tabular}{|c|c|c|c|c|c|}
\hline \multicolumn{6}{|c|}{ Copper Sulphate. } \\
\hline$c$. & $l$. & $\begin{array}{l}\text { Region in } \\
\text { Spectrum. }\end{array}$ & $(1-p)$ & l. $\varepsilon$. & A. \\
\hline $\begin{array}{l}0.2856 \\
0.2842\end{array}$ & $\begin{array}{c}7 \cdot 64 \\
22 \cdot 87\end{array}$ & $\begin{array}{c}\lambda . \\
\quad \lambda \cdot \\
627 \cdot 7-599 \cdot 4 \\
599 \cdot 4-574 \cdot 2 \\
574 \cdot 2-551 \cdot 6 \\
551 \cdot 6-534 \cdot 1 \\
53 \cdot 1-518 \cdot 2 \\
551 \cdot 6-534 \cdot 1 \\
534 \cdot 1-518 \cdot 2 \\
518 \cdot 2-502 \cdot 3 \\
502 \cdot 3-488 \cdot 3 \\
518 \cdot 2-502 \cdot 3 \\
502 \cdot 3-488 \cdot 3 \\
488 \cdot 3-474 \cdot 6 \\
474 \cdot 6-462 \cdot 8 \\
462 \cdot 8-452 \cdot 2 \\
452 \cdot 2-443 \cdot 1 \\
443 \cdot 1-434 \cdot 2 \\
434 \cdot 2-427 \cdot 0 \\
627 \cdot 7-599 \cdot 4 \\
599 \cdot 4-574 \cdot 2 \\
574 \cdot 2-551 \cdot 6 \\
551 \cdot 6-534 \cdot 1 \\
574 \cdot 2-551 \cdot 6 \\
551 \cdot 6-534 \cdot 1 \\
534 \cdot 1-518 \cdot 2 \\
518 \cdot 2-502 \cdot 3 \\
502 \cdot 3-488 \cdot 3\end{array}$ & $\begin{array}{l}0 \cdot 083 \\
0 \cdot 2944 \\
0 \cdot 4930 \\
0 \cdot 6985 \\
0 \cdot 8171 \\
0 \cdot 0611 \\
0 \cdot 22: 20 \\
0 \cdot 4454 \\
0 \cdot 6716 \\
0 \cdot 0697 \\
0 \cdot 2490 \\
0 \cdot 5021 \\
0 \cdot 6734 \\
0 \cdot 7723 \\
08103 \\
0 \cdot 7873 \\
0 \cdot 7846 \\
0 \cdot 0614 \\
0 \cdot 2290 \\
0 \cdot 4700 \\
0 \cdot 6880 \\
0 \cdot 1077 \\
0 \cdot 2930 \\
0 \cdot 5086 \\
0 \cdot 6884 \\
0 \cdot 8377\end{array}$ & $\begin{array}{l}1 \cdot 08096 \\
0 \cdot 53102 \\
0 \cdot 30714 \\
0 \cdot 15582 \\
0 \cdot 08774 \\
1 \cdot 21424 \\
0 \cdot 65357 \\
0 \cdot 35130 \\
0 \cdot 17286 \\
1 \cdot 15643 \\
0 \cdot 60386 \\
0 \cdot 29925 \\
0 \cdot 17176 \\
0 \cdot 11220 \\
0 \cdot 09137 \\
0 \cdot 10384 \\
0 \cdot 10535 \\
1 \cdot 21468 \\
0.64017 \\
0 \cdot 32791 \\
0 \cdot 16242 \\
0 \cdot 96793 \\
0 \cdot 53305 \\
0 \cdot 29361 \\
0 \cdot 16216 \\
0 \cdot 07690\end{array}$ & $\begin{array}{c}1 \cdot 89 \\
3 \cdot 85 \\
6 \cdot 66 \\
13 \cdot 12 \\
23 \cdot 25 \\
12 \cdot 79 \\
23 \cdot 76 \\
44 \cdot 20 \\
89 \cdot 8 \\
47 \cdot 07 \\
90 \cdot 15 \\
181 \cdot 9 \\
316 \cdot 9 \\
485 \cdot 2 \\
595 \cdot 8 \\
523 \cdot 0 \\
516 \cdot 7 \\
1 \cdot 796 \\
3 \cdot 408 \\
6 \cdot 654 \\
13 \cdot 43 \\
6 \cdot 715 \\
12 \cdot 19 \\
22 \cdot 14 \\
4008 \\
84 \cdot 52\end{array}$ \\
\hline \multicolumn{6}{|c|}{ Copper Chloride. } \\
\hline $4 \cdot 211$ & 1.006 & $\begin{array}{l}599 \cdot 4-574 \cdot 2 \\
574 \cdot 2-551 \cdot 6 \\
551 \cdot 6-534 \cdot 1 \\
534 \cdot 1-518 \cdot 2 \\
518 \cdot 2-502 \cdot 3 \\
502 \cdot 3-488 \cdot 3 \\
488 \cdot 3-474 \cdot 6 \\
474 \cdot 6-462 \cdot 8 \\
462 \cdot 8-452 \cdot 2 \\
452 \cdot 2-443 \cdot 1\end{array}$ & $\begin{array}{l}0.0799 \\
0.2403 \\
0.4971 \\
0.6987 \\
0.8339 \\
0.8764 \\
0.7981 \\
0.6591 \\
0.4131 \\
0.2104\end{array}$ & $\begin{array}{l}1.09711 \\
0 \cdot 61918 \\
0.30355 \\
0.15573 \\
0.07888 \\
0.05731 \\
0.09797 \\
0.18109 \\
0.38395 \\
0.67687\end{array}$ & $\begin{array}{r}3 \cdot 86 \\
6 \cdot 84 \\
13 \cdot 95 \\
27 \cdot 20 \\
53 \cdot 70 \\
73 \cdot 92 \\
43 \cdot 24 \\
23 \cdot 39 \\
11 \cdot 03 \\
6 \cdot 26\end{array}$ \\
\hline
\end{tabular}

Phil. Mag. S. 5. Vol. 33. No. 203. April 1892. 2 A 
Table VIII. (continued.)

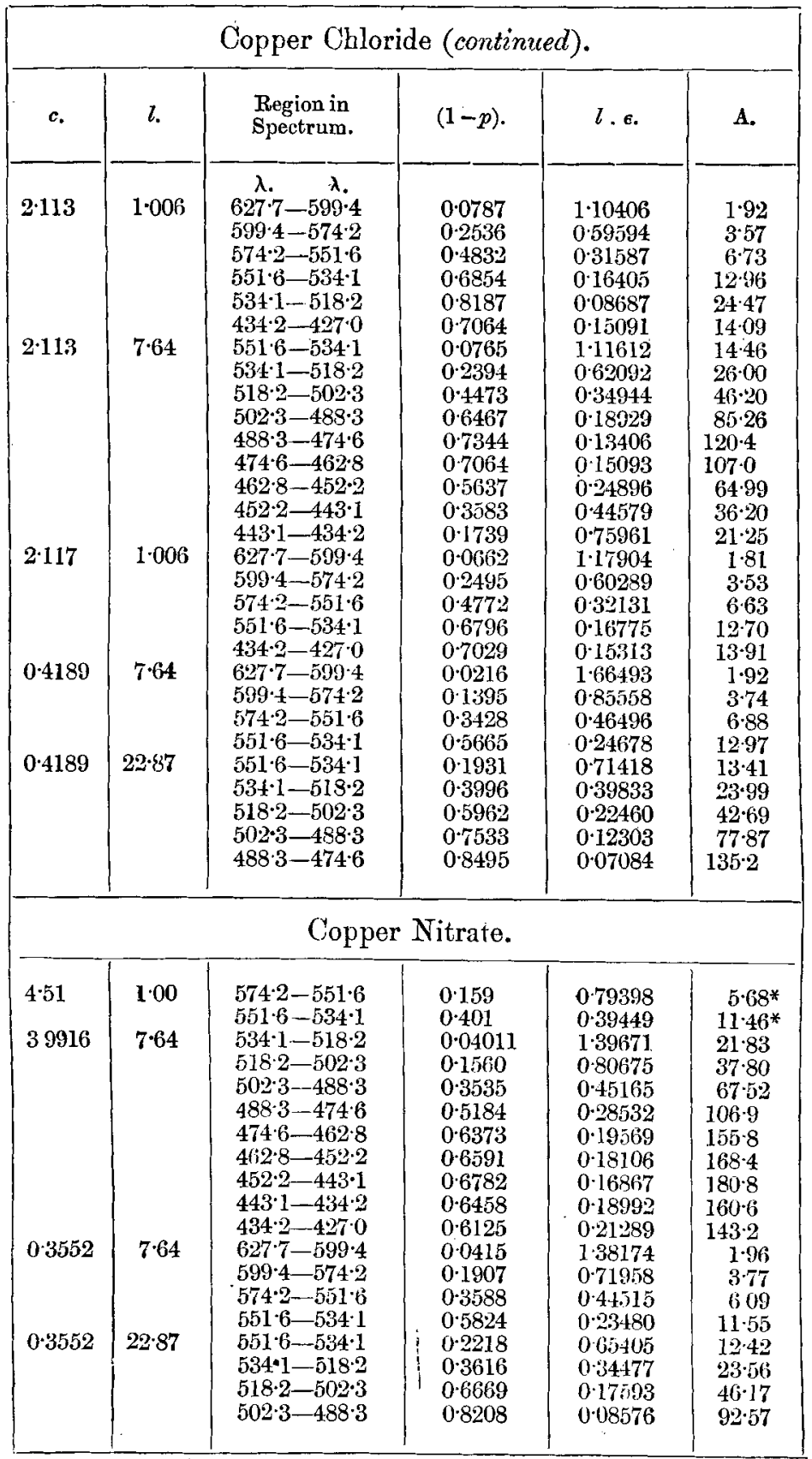

* These numbers were obtained with light which was not parallel. 
The refractive indices of the solutions were determined for sodium light as follows:-

\begin{tabular}{|c|c|c|}
\hline Substance. & Concentration. & Refractive Index. \\
\hline $\begin{array}{ccc}\mathrm{CuSO}_{4} & \ldots \ldots \ldots \ldots . . . \\
\mathrm{CuCl}_{2} & \ldots \ldots \ldots \ldots \ldots . . . \\
\mathrm{C}_{2} & \ldots \ldots \ldots \ldots . . .\end{array}$ & $\begin{array}{l}2 \cdot 1 \\
0 \cdot 28 \\
4 \cdot 2 \\
2 \cdot 1\end{array}$ & $\begin{array}{l}1 \cdot 365 \\
1 \cdot 336 \\
1 \cdot 388 \\
1 \cdot 362\end{array}$ \\
\hline
\end{tabular}

Table IX. contains the absorption-ratios of all the solutions examined. The absorption-ratio for any substance in solutions of different concentration can be regarded as constant when the differences of concentration are small. The mean, therefore, of the numbers obtained with the solutions of nearly the same concentration has been taken.

TABLE IX.

\begin{tabular}{|c|c|c|c|c|c|c|c|}
\hline \multirow{2}{*}{$\begin{array}{l}\text { Position in } \\
\text { Spectrum. }\end{array}$} & \multicolumn{2}{|c|}{$\mathrm{CuSO}_{4 .}$} & \multicolumn{3}{|c|}{$\mathrm{CuCl}_{2}$} & \multicolumn{2}{|c|}{$\mathrm{Ou}\left(\mathrm{NO}_{3}\right)_{2}$} \\
\hline & 2 eq. & 0.28 eq. & 4 eq. & 2 eq. & $0.4 \mathrm{eq}$. & 4 eq. & 0.35 eq. \\
\hline$\lambda$. & & & & & & & \\
\hline $627 \cdot 7-599 \cdot 4$ & $1 \cdot 89$ & $1 \cdot 79$ & & 1.86 & 1.92 & ....... & 1.96 \\
\hline $599 \cdot 4-574 \cdot 2$ & $3 \cdot 85$ & $3 \cdot 41$ & $3 \cdot 86$ & 355 & $3 \cdot 74$ & & $3 \cdot 77$ \\
\hline $574 \cdot 2-551 \cdot 6$ & $6 \cdot 66$ & 6.81 & 684 & 668 & $6 \cdot 88$ & $5 \cdot 68$ & 609 \\
\hline $551 \cdot 6-534 \cdot 1$ & 1295 & $12 \cdot 65$ & 13.95 & $13 \cdot 41$ & $13 \cdot 19$ & $11 \cdot 46$ & $11 \cdot 99$ \\
\hline $534 \cdot 1-5182$ & $23 \cdot 51$ & 22.05 & $27 \cdot 20$ & $25 \cdot 23$ & $23 \cdot 99$ & 21.83 & 23.56 \\
\hline $518 \cdot 2-502 \cdot 3$ & $45 \cdot 63$ & $40 \cdot 45$ & 5370 & $46 \cdot 20$ & $42 \cdot 69$ & $37 \cdot 80$ & $46 \cdot 17$ \\
\hline $502 \cdot 3-488 \cdot 3$ & 89.97 & $8 \div 73$ & $73 \cdot 92$ & $85 \cdot 26$ & 77.87 & 67.52 & 9257 \\
\hline $4883-474 \cdot 6$ & 181.9 & $143 \cdot 2$ & $43 \cdot 24$ & $120 \cdot 4$ & $135 \cdot 2$ & $108 \cdot 9$ & \\
\hline $474 \cdot 6-4628$ & $316 \cdot 9$ & ....... & 2339 & $107 \cdot 0$ & $\ldots \ldots$ & $155 \cdot 8$ & ....... \\
\hline $462 \cdot 8-452 \cdot 2$ & $485 \cdot 2$ & ...... & 11.03 & 64.99 & $\ldots \ldots$ & $168 \cdot 4$ & $\ldots \ldots$ \\
\hline $452 \cdot 2-443$ & $595 \cdot 8$ & ....... & 626 & $36 \cdot 20$ & ....... & $180 \cdot 8$ & ....... \\
\hline $443 \cdot 1--4$ & 5230 & & ....... & $21 \cdot 25$ & ........ & $160 \cdot 6$ & ...... \\
\hline $434 \cdot 2-42$ & 516.7 & & ...... & 14:00 & ....... & $143 \cdot 2$ & ....... \\
\hline
\end{tabular}

The absorption-spectrum of copper sulphate has already been measured by Glan*. He has given his results in the form of fractions of light transmitted - (the quantity which I have called $(1-p)$. The light, in Glan's experiments, passed vertically upwards through a glass trough, in the lower part of which was a layer of strong copper sulphate solution, and floating upon this a layer of distilled water. The fraction of the light transmitted was measured, the water and solution mixed together, and the measurement repeated. In order to compare my numbers with those of Glan I have calculated

* Glan, Wied. Ann. iii. p. 54 (1878). 
from the measurements on the strong solutions the part of the light which would be left after passing through a layer of 1 centim. thickness of a solution containing 2 gram equivs. of $\mathrm{CuSO}_{4}$ in 1 litre, and from the dilute solutions, the fraction which would remain after passing through 8 centim. of a solution containing $0 \cdot 25$ equivs. The results of the calculation are contained in the following Table:-

Table X.

\begin{tabular}{|c|c|c|c|}
\hline $\begin{array}{c}\text { Region in } \\
\text { Spectrum (mean } \lambda)\end{array}$ & $\begin{array}{c}(1-p) \\
\text { Conc. Solution. }\end{array}$ & $\begin{array}{c}(1-p) \\
\text { Dil. Solution. }\end{array}$ & Difference. \\
\hline $\mathbf{6 1 2 . 6}$ & 0.078 & 0.077 & +0.001 \\
586.1 & 0.302 & 0.259 & +0.043 \\
563.6 & 0.501 & 0.509 & -0.008 \\
543.3 & 0.701 & 0.695 & +0.006 \\
526.1 & 0.822 & 0.811 & +0.011 \\
509.7 & 0.904 & 0.892 & +0.012 \\
493.5 & 0.950 & 0.946 & +0.004 \\
$\mathbf{4 8 1 . 5}$ & 0.975 & 0.968 & +0.007 \\
\hline
\end{tabular}

Glan's numbers are given for comparison in the following Table :-

Table XI.

\begin{tabular}{|c|c|c|c|c|}
\hline Mean $\lambda$. & $(1-p)$ conc. & $(1-p)$ dil. & Difference. & Dilution. \\
\hline 674 & 0.077 & 0.073 & +0.004 & $1 / 7$ \\
659 & 0.155 & 0.150 & +0.005 & $1 / 7$ \\
626 & 0.336 & 0.330 & +0.006 & $1 / 5$ \\
5557 & 0.449 & 0.441 & +0.008 & $1 / 3$ \\
557 & 0.510 & 0.507 & +0.003 & $1 / 7$ \\
525 & 0.822 & 0.813 & +0.009 & $1 / 3$ \\
525 & 0.848 & 0.854 & -0.006 & $1 / 7$ \\
\hline
\end{tabular}

With the exception of one number in each set of experiments, the differences are all in the same direction. They are, it is true, about the same magnitude as the experimental error, but the circumstance that the two sets of numbers were obtained by different methods and with different instruments seems to point to the existence of a real difference between the absorption of the strong and dilute solutions of $\mathrm{CuSO}_{4}$. Jt. is not, unfortunately, possible to compare the absolute magnitudes of the absorption, as Glan has only given the relative concentrations of his solutions (last column Table XI.). Glan's strongest solutions were, however, evidently saturated, 


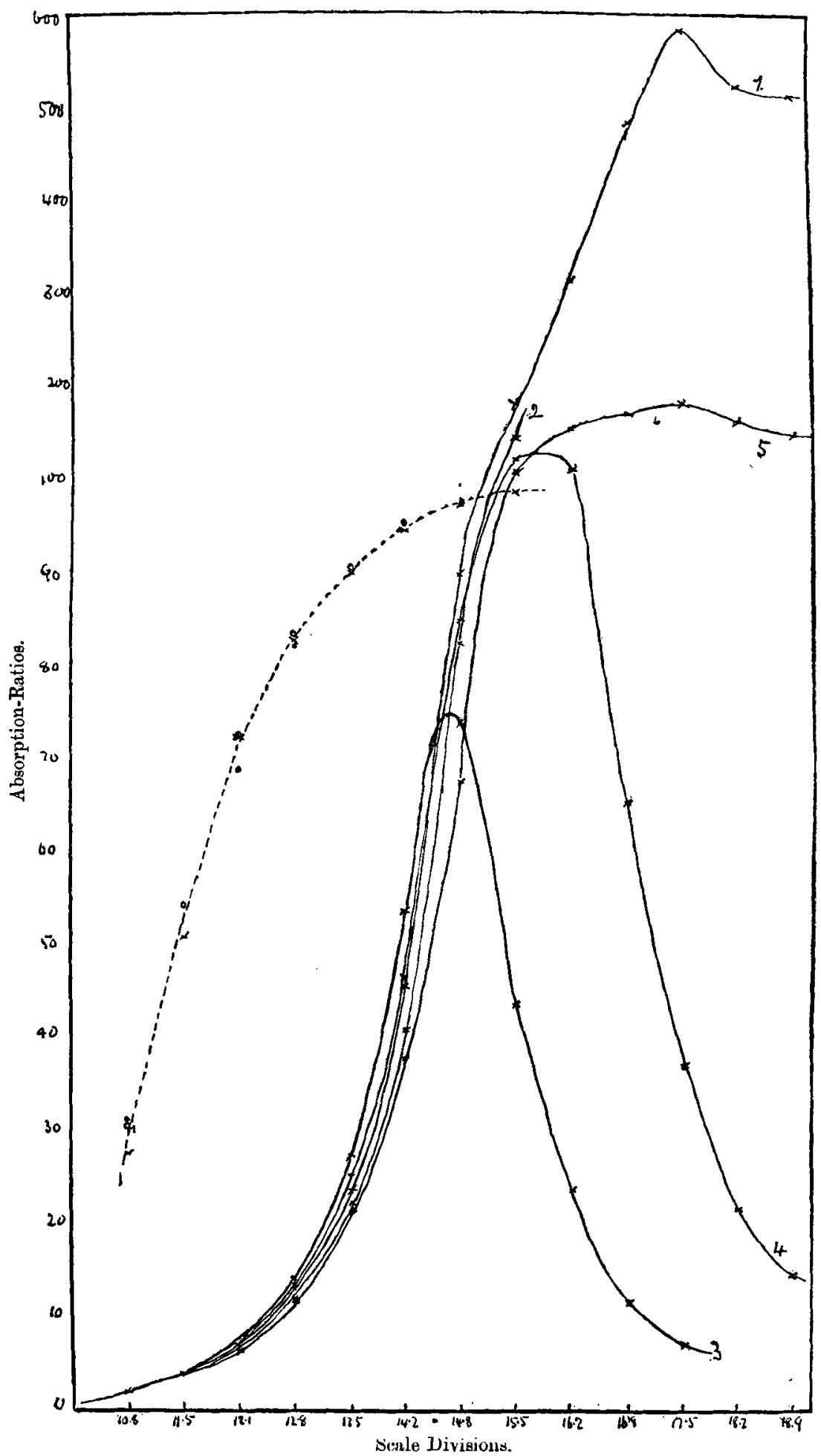


or nearly so, and his experiments are therefore comparable with mine.

The changes in the absorption-spectra of the solutions which occur when the concentration is changed are very clearly visible in the curves which represent the absorption-ratios. These are drawn for convenience with the divisions of the tangent-screw as abscissæe (instead of wave-lengths), and the values of the absorption-ratios as ordinates. Curves 1 and 2 belong to the strong and dilute solutions of copper sulphate, 3 and 4 represent the absorption-ratios of the copper-chloride solutions containing about 4 and 2 equivalents in 1 litre, and 5 belongs to $\mathrm{Cu}\left(\mathrm{NO}_{3}\right)_{2}$. The curves of the most dilute solutions of the three salts lie very close together and are almost identical with No. 2. The great similarity of the absorptions of these three solutions is best seen, not by comparing their absorption-ratios, hut by comparing the fractions of the light transmitted by them, calculated for solutions containing the same amount of copper, and for unit length of layer. The comparison is carried out in Table XII. Comparing the absorptions in this way, it is possible to see whether the differences between them are greater than the experimental error or not. This is very difficult when the numbers are calculated as absorption-ratios, as the errors in the measurements are much exaggerated in parts of the spectrum where the absorption is small, and vice versâ.

\section{Table XII.*}

\begin{tabular}{|c|c|c|c|c|c|}
\hline $\begin{array}{l}\text { Region in } \\
\text { Spectrum. }\end{array}$ & $\mathrm{CuSO}_{4}$. & $\mathrm{CuCl}_{2}$. & $\begin{array}{l}\mathrm{CuSO}_{4} \\
\quad-\mathrm{CuCl}_{2} .\end{array}$ & $\left(\mathrm{CuNO}_{\mathrm{a}}\right)_{2^{\circ}}$ & $\mathrm{CuCl}_{2}-\mathrm{Cu}\left(\mathrm{NO}_{3}\right)_{2}$ \\
\hline $627 \cdot 7-599 \cdot 4$ & $0 \cdot 2775$ & $0: 3018$ & $-0.02+3$ & 0.3096 & -0.0078 \\
\hline $599 \cdot 4-574 \cdot 2$ & 0.5089 & 0.5403 & -0.0314 & 0.5430 & -0.0027 \\
\hline $574 \cdot 2-551 \cdot 6$ & 0.7130 & 0.7157 & -0.0027 & $0 \cdot 6854$ & +0.0303 \\
\hline $551 \cdot 6-534 \cdot 1$ & 0.8333 & 0.8398 & -0.0065 & 08254 & +0.0144 \\
\hline $534 \cdot 1-518 \cdot 2$ & 0.9008 & 0.9087 & -0.0079 & 0.9069 & +0.0018 \\
\hline $518 \cdot 2-502 \cdot 3$ & $0 \cdot 9447$ & 0.9474 & -0.0027 & 0.9513 & -0.0039 \\
\hline $502 \cdot 3-488 \cdot 3$ & 09725 & 09709 & +0.0016 & 0.9759 & -0.0050 \\
\hline $488 \cdot 3-474 \cdot 6$ & 0.9840 & 0.9831 & +0.0009 & & \\
\hline
\end{tabular}

The numbers for copper chloride and copper nitrate are very similar, the differences are scarcely larger than the experimental error and vary in sign. The differences between copper sulphate and copper chloride, on the other hand, are nearly all in the same direction and sometimes considerably exceed the error of experiment.

* The numbers are calculated for solutions containing I equivalent in 1 litre. 


\section{Conclusions.}

It is at once noticeable that the curves representing the absorption-ratios of all the solutions appear to start out from the same point at the red end of the spectrum and for a short distance to follow an identical course, diverging more and more widely as the wave-length decreases. It appears natural to attribute this absorption in the red, which is common to all the solutions, to the common constituent copper, and to attribute the differences partly to the absorption exercised by the acid radical itself, and partly to the influence which it has on the vibrations of the copper. Something analogous to this influence of the acid radical on the absorption of the copper was observed by Abney and Festing* in their work on the absorption-spectra of organic and other compounds in the infra-red. They found that a number of definite lines in these spectra undoubtedly were due to hydrogen, but that the number of them and their relative intensity in any spectrum were dependent on the other atoms with which the hydrogen was combined. The investigations of Hartley, Krüss, Vogel, and others on the absorption-spectra of organic compounds have shown that the absorption of light by a substance is dependent on its chemical constitution. Every change in the nature, number, or linking of the atoms causes a corresponding change in the absorption-spectrum. So that in general when two substances are chemically combined the absorptionspectrum of the compound will be different from that of the constituents. On the other hand, when two substances which are not chemically united exist together in a solution, the absorption-spectrum is the sum of the two separate spectra. Arguing backwards, it seems probable that, if two substances in a solution absorb light independently of one another, so that replacing one of them by something else makes no difference in the absorption-spectrum of the other, then they are not chemically combined. In the dilute solutions of the three copper salts examined this appears to be-at least very nearly - the case. Replacing $\mathrm{SO}_{4}$ by $\mathrm{Cl}_{2}$ or by $\left(\mathrm{NO}_{3}\right)_{2}$ makes very little difference in the absorption, though in the strong solutions the difference made by such a replacement is very large. One wonld, therefore, seem to be forced to the conclusion that only in the strong solutions is the copper really chemically combined with the acid part of the salt, and that as the solutions become more and more dilute the dissociation of the salt becomes greater and greater. It has already been pointed out at the beginning of this paper that

* Pbil. Trans. (1881), Part III. p. 887. 
in general salts in aqueous solution behave in the same way as these copper salts, though exceptions are known.

It only remains to compare briefly the results thus arrived at with existing theories of solution.

(1) According to the theory of Arrhenius the electrolytic dissociation in the most dilute copper solutions which were examined is by no means complete, and therefore the absorption-spectra of the three solutions should not be identical.

The degree of dissociation is calculated from the numbers of Kohlrausch* for copper sulphate, of J. Trötsch $\dagger$ and J. H. van $t^{\prime}$ Hoff and Reicher $\ddagger$ for copper chloride, and of Long $\$$ for copper nitrate. The numbers obtained are as follow's :-

$$
\begin{aligned}
& \mathrm{CuSO}_{4}, \quad 0 \cdot 2856 \text { eq. in } 11 ., \mu=344, \mu_{\infty}=1086 \text {, } \\
& \text { dissociation }=31 \cdot 7 \text { per cent. }
\end{aligned}
$$

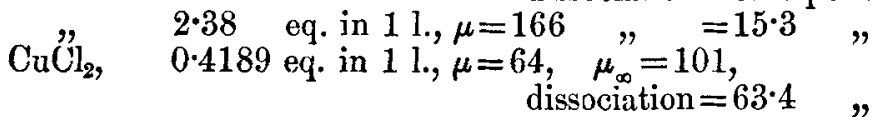

$$
\begin{aligned}
& \mathrm{Cu}\left(\mathrm{NO}_{3}\right)_{2}, 0.3552 \text { eq. in } 11 ., \mu=65^{\circ} 8, \mu_{\mathrm{oo}}=100 \text { ?, } \\
& \text { dissociation }=6 \dot{5} \cdot 8,
\end{aligned}
$$

It is interesting to observe that the solutions of chloride and nitrate of copper in which the dissociation is far advanced and nearly to the same extent, possess almost identical absorption-spectra, whereas that of copper sulphate is noticeably diflerent, which fact is in agreement with the theory, the dissociation in the copper-sulphate solution being very much less advanced than in the others.

It is as well to draw attention to the fact that before one can determine whether the limit of dilution after which the absorption no longer changes is identical with the limit at which the dissociation is complete, it may be necessary to examine the absorption in the ultra-violet and perhaps in the infra-red. The experiments in the first part of this paper with copper chloride seem to show that changes go on in the invisible violet after they have ceased in the visible part of the spectrum.

(2) Knoblauch has explained the alterations in the spectra of certain salts by assuming a hydrolytic dissociation in the more dilute solutions. In the case of copper salts there appears to be no reason for assuming that such a dissociation takes place to any extent. A hydrolytic dissociation of a

\footnotetext{
* Wied. Ann. vi. p. 1 (1879) ; ibid. xxvi. p. 188 (1885).

† Wied. Ann. xli. p. 259 (1890).

$\ddagger$ Zeitschrift. Phys. Chem. iii. p. 198 (1889).

\$ Wied. Ann. xi. p. 37 (1880).
} 
copper salt would lead (as it does with chromium salts) to a separation of hydroxide. The small amount of precipitate which forms in solutions of cupric salts after standing for some time appears to be due to impurities in the water (chiefly ammonia and carbon dioxide).

(3) According to the theory of Armstrong* and Traube $\dagger$, the changes in the absorption-spectra which occur on passing from concentrated to dilute solutions are due to the larger aggregates of molecules which exist in the concentrated solutions breaking up into smaller molecules. According to this theory, the molecules of the salt, even in the most dilute solutions, still exist as such; and these dilute solutions might therefore be expected to show characteristic differences, similar to those observed in the strong solutions. This at any rate in the case of cupric salts is not the case in the visible part of the spectrum.

(4) The changes of colour which the solutions of copper chloride exhibit when its solution is diluted have long been regarded as due to the formation of different bydrates. If we admit with Pickering the existence of hydrates in dilute solutions containing 1000 or more molecules of water, it is conceivable that two salts of the same metal with colourless acids should have in dilute solution the same spectrum, for the influence exercised on the vibrations of the metal by the acid ridical would become negligible compared with that exercised by the 1000 water molecules. Two compounds such as $\mathrm{CuCl}_{2}+1000 \mathrm{H}_{2} \mathrm{O}$ and $\mathrm{CuSO}_{4}+1000 \mathrm{H}_{2} \mathrm{O}$ might well have the same spectrum. The experiments are hardly complete enough to allow of any very definite conclusion on this point, but as I am occupied with further experiments on the absorption-spectra I hope to return to it on another occasion.

The large changes of colour which often occur on diluting the solutions of the halogen salts of heavy metals may perhaps be connected not with hydrates but with the halogen. Gladstone $f$ has pointed out that the spectra of strong solutions of the bromides of platinum, gold, copper, and of potassium palladium bromide, all appear to be made up of the absorptions of bromine-water and of a salt of the metal with a colourless acid. It appears as though the halogen when combined with a metal exercised its absorption in the same way as in the free state, but modified to a greater or smaller extent by the metal with which it is combined.

The following is a summary of the results arrived at :-

* J. Chem. Soc. liii. p. 116 (1888).

+ Berichte, xxiii. p. 3582 (1890).

$\ddagger$ Gladstone, Phil, Mag. [4] xiv. p. 418 (1857). 
(1) The absorption-spectra of the three salts examined undergo changes on diluting their solutions.

(2) These changes are of such a nature that the spectra tend to become identical in dilute solutions.

(3) The results of other observers show on the whole that salts of other metals behave in a similar way.

(4) The behaviour of the salts examined leads to the conclusion that, in strong solutions, the acid and basic parts of the salts are associated in producing absorption of light, while in dilute solutions they act independently in doing so.

(5) These results are in substantial agreement with the hypothesis of electrolytic dissociation.

(6) The results cannot be satisfactorily explained on the hypothesis of a hydrolytic dissociation, or on that of molecular aggregates.

In conclusion, I take this opportunity of expressing my thanks to Professor H. B. Dixon, at whose suggestion this investigation was begun, and also to Professor A. Schuster for the kindness with which he placed the Vierordt spectrophotometer and other apparatus at my disposal, and for much valuable advice in carrying out the work.

XXXVI. On Chemical Equilibrium in Mixed Electrolytes. By Dr. G. Gone, F'.R.S.*

TN various researches $I$ have shown that any change occurring in the molecular or chemical constitution of an electrolyte may be easily and quickly detected, and its amount and rate to a certain extent measured, either by the voltaic balance method, or by the simple plan of immersing a suitable voltaic pair of metals in the liquid successively at different periods of time, and noting either the degree of voltaic energy, electromotive force, or strength of current produced; and I have shown that in certain cases, the mixture of electrolytes, especially that of an aqueous solution of a halogen with one of a salt or base (and in some cases a very dilute solution of an acid with one of a salt), the liquid mixture does not at once attain its final or fixed state at $16^{\circ} \mathrm{C}$, but attains it rapidly on the application of heat. (See "Method of Examining Rate of Chemical Change in Aqueous Solutions," Proc. Roy. Soc. March 14, 1890, p. 440. "On the Molecular Constitution of Isomeric Solutions," Phil. Mag. Oct. 1889, p. 289. "Method of Measuring Loss of Energy due to Chemical Union \&c.," Phil. Mag. Jan. 1892, p. 28.)

* Communicated by the Author. 